\title{
Review Article \\ Looking for the Mechanism of Action of Thyroid Hormone
}

\author{
Jamshed R. Tata \\ Division of Developmental Biology, The National Institute for Medical Research, The Ridgeway, Mill Hill, London NW7 2HA, UK \\ Correspondence should be addressed to Jamshed R. Tata, jtata@nimr.mrc.ac.uk
}

Received 8 February 2011; Accepted 29 March 2011

Academic Editor: Laurent Sachs

Copyright ( 2011 Jamshed R. Tata. This is an open access article distributed under the Creative Commons Attribution License, which permits unrestricted use, distribution, and reproduction in any medium, provided the original work is properly cited.

\begin{abstract}
The mechanisms of action of thyroid hormone (TH), characterized by multiple physiological activities, proposed over the last 80 years are a reflection of the progression of our knowledge about eukaryotic signalling processes. The cumulative knowledge gained raises the question as to what is so special about the action of this hormone. The discovery in the 1980s that TH receptors belong to the family of nuclear transcription factors that regulate the expression of hormonal target genes was an important milestone. TH receptors are highly organized within the chromatin structure, which itself is modified by several chromosomal and nonchromosomal factors, in the presence and absence of the hormone. Recently, some investigators have suggested that TH acts via both genomic and nongenomic mechanisms and introduced the concept of networking within cellular complexes. While one cannot as yet precisely describe the mechanism of thyroid hormone action, I will attempt here to point out the present thinking and future directions to achieve this goal in the light of the historical background.
\end{abstract}

\section{Introduction}

Even before L-thyroxine $\left(3,3^{\prime}, 5,5^{\prime}\right.$-tetraiodothyronie or $\left.\mathrm{T}_{4}\right)$ was identified by Kendall in 1919 as the active thyroid hormone in the thyroid gland, and later synthesized by Harington in 1926 [1], physiologists and biochemists had already proposed in the first two decades of the twentieth century several mechanisms of actions of the hormone (see [2]). Although the hormone was known to be endowed with multiple metabolic and developmental activities, most studies at first focused on the calorigenic action of the hormone, largely because of the clinical association between basal metabolic rate (BMR) and thyroid gland morphology and activity. The dramatic role of thyroid hormone in amphibian metamorphosis, demonstrated by Gudermatsch in 1911, was largely ignored for twenty years by those interested in explaining the biochemical mechanisms underlying thyroid hormone action.

It took nearly 35 years after thyroxine that 3,3',5-triiodoL-thyronine $\left(\mathrm{T}_{3}\right)$ was identified, almost simultaneously as a constituent of thyroglobulin in the thyroid gland and in human blood in the laboratories of Roche in Paris and PittRivers in London. Not long after that, several laboratories confirmed that $T_{3}$ is biologically more active than $T_{4}$ in several physiological assays, such as BMR, amphibian metamorphosis, lipid metabolism, and pituitary function $[2,3]$. A larger part of $T_{3}$ in the blood and peripheral tissues of most vertebrates is derived from the partial deiodination of $\mathrm{T}_{4}$ than was produced in the thyroid gland. This conversion has given rise to the commonly held view that $T_{3}$ is the biologically active thyroid hormone while $\mathrm{T}_{4}$ is the prohormone, the enzyme responsible for the conversion, one of the deiodinases which remove I atoms from the inner and outer rings of $\mathrm{T}_{4}$ and $\mathrm{T}_{3}$. The deiodinases are considered to be important in the dynamics of TH activity [4]. For the purposes of this review, I shall consider $T_{3}$ as the biologically active thyroid hormone and $\mathrm{T}_{4}$ as the pro-hormone, while the term $\mathrm{TH}$ will include any of their derivatives or conjugates with biological activity.

A major advance in our understanding of the biochemical and molecular basis of the action of TH was the identification, cloning, and characterization of its receptors (TRs) in 1986 in the laboratories of Vennström [5] and Evans [6]. These receptors are members of a large multigenic family of transcription factors which are activated by hormonal or other signalling molecules. TRs are integral chromosomal proteins whose structure and chemical nature is modified by $\mathrm{TH}$. The liganded receptor is such that they would modify 
TABLE 1: Multiplicity of physiological and biochemical actions of thyroid hormone.

\begin{tabular}{ll}
\hline Growth and developmental actions & Metabolic actions \\
\hline Rate of postnatal growth of many mammalian and avian tissues & $\begin{array}{l}\text { Regulation of basal metabolic rate in endotherms } \\
\text { Movement of water and } \mathrm{Na}^{+} \text {ions across cell } \\
\text { membranes } \\
\text { Functional and biochemical maturation of fetal brain and bone }\end{array}$ \\
$\begin{array}{l}\text { Morphogenesis, gene switching, and cell death in amphibian larval } \\
\text { metamorphosis }\end{array}$ & $\begin{array}{l}\text { Regulation of metabolism of cholesterol and other } \\
\text { lipids }\end{array}$ \\
$\begin{array}{l}\text { Control of molting in birds } \\
\text { Regulation of synthesis of mitochondrial respiratory enzymes and } \\
\text { membranes }\end{array}$ & $\begin{array}{l}\text { Nitrogen (urea, creatine) metabolism } \\
\text { Control of oxidative phosphorylation and energy } \\
\text { metabolism }\end{array}$ \\
\hline
\end{tabular}

the interaction between the receptor and its target genes, leading, directly or indirectly, to the physiological action of the hormone [7]. Much progress has been made in the last 20 years in enhancing our knowledge of chromosomal or chromatin structure, so that it is not surprising that a substantial amount has been learnt about the possible ways in which the structural and biochemical modifications of chromatin would modulate the action of thyroid hormone [8]. These advances have most recently led to exploring the processes of networking within and between cells and wider questions of systems biology for further exploration of the search for mechanism of hormone action $[9,10]$.

This paper is a brief review of some historical and current thinking and work relating to the mechanism of action of thyroid hormone covering the period of the last 80-90 years and gives a largely, but not uniquely, personal point of view of the author. It is not meant to be a comprehensive review of thyroid hormone action. If any of the readers' work or ideas are not cited below, it is not the author's intention to diminish the importance of their contributions to this field of research.

\section{Multiple Effects but Unique Mechanism of Action?}

Can one explain the multiple biological effects of thyroid hormone with a unique mechanism of action? First, let us consider the multiplicity of actions. Towards the end of the 19th century, physicians and surgeons in England, France, and Switzerland established the link between the thyroid gland and iodine deficiency disorders such as goitre, cretinism, and myxoedema in man. By the early 20th century, removal of the gland in experimental animals and grafting it back to reverse the effects of thyroidectomy corroborated the beneficial effects of administering ovine, bovine, and porcine thyroid powder or extracts for the treatment of patients suffering from myxoedema, cretinism and growth retardation in children, or other consequences of thyroid deficiency. The chance observation in Naples by Gudernatsch that feeding pieces or extracts of mammalian thyroid gland to frog tadpoles precociously induced metamorphosis emphasized the important role of thyroid hormone in regulating postembryonic growth and development in all vertebrates [11]. The establishment of L-thyroxine and
triiodo-L-thyronine as the biologically active principles in the thyroid and peripheral tissues and the availability of synthetic $\mathrm{T}_{4}$ and $\mathrm{T}_{3}$, and many of their biologically active and inactive homologues, made it possible to establish, both qualitatively and quantitatively, the characteristics of the multiple hormonal activities.

In Table 1 are listed the major physiological actions of thyroid hormone, which can be loosely subdivided into two groups: (a) those that regulate metabolic functions and (b) those that control growth and development. It is immediately obvious that the biological responses to the hormone vary according to species, tissue, and developmental stage. Generally, the metabolic responses are most visible in endotherms, often manifested as basal metabolic rate $(\mathrm{BMR})$, water retention lipid metabolism, and so forth. The hormonal effects on growth and development are particularly evident in ectotherms, and less during the postembryonic or perinatal period in mammals and other warm-blooded vertebrates. It should be emphasized that separation of the physiological and biochemical actions of $\mathrm{TH}$ into two categories, as in Table 1, does not imply a sharp boundary between the two, and that there can be some overlap determined by the variables mentioned above.

An even more striking example of the multiple responses to $\mathrm{TH}$ is seen when comparing tissue-specific responses to the hormone during amphibian metamorphosis, illustrated in Table 2. The process can be precociously induced by the administration of exogenous $\mathrm{TH}$ to immature tadpoles, which confirms the fact that the developmental programme is well in place before the larval thyroid gland is fully developed and can begin to secrete the hormone [12]. An important feature of the multiplicity of actions that emerges from Table 2 is that no two tissues or groups of cells exhibit the same hormonal responses, which range from de novo morphogenesis, as for limb and lung development, functional reprogramming, as for the brain, liver, and eye, total or partial tissue loss of tissue, as seen for the tadpole tail and gills. Similar processes are discernible, albeit less clearly and more attenuated, in other vertebrates and mammals during the perinatal period. Indeed, tissue-specific gene switching is central to hormonal signalling, not only as regards $\mathrm{TH}$ but also many steroid and protein hormones that regulate growth and development in general.

Early investigators were intrigued by how the relatively simple, but quite unique, molecule of a hormone as $\mathrm{TH}$ 
TABLE 2: Morphological and biochemical responses to thyroid hormone during amphibian metamorphosis.

\begin{tabular}{|c|c|c|}
\hline \multirow{2}{*}{ Tissue } & \multicolumn{2}{|c|}{ Response } \\
\hline & Morphological & Biochemical \\
\hline Brain & $\begin{array}{l}\text { Restructuring, axon guidance, axon } \\
\text { growth, cell proliferation, and death }\end{array}$ & $\begin{array}{l}\text { Cell division, apoptosis, and new } \\
\text { protein synthesis }\end{array}$ \\
\hline Liver & $\begin{array}{l}\text { Restructuring, functional } \\
\text { differentiation }\end{array}$ & $\begin{array}{l}\text { Induction of urea cycle enzymes and } \\
\text { albumin; larval to adult haemoglobin } \\
\text { gene switching }\end{array}$ \\
\hline Eye & $\begin{array}{l}\text { Repositioning; new retinal neurones } \\
\text { and connections; lens structure }\end{array}$ & $\begin{array}{c}\text { Visual pigment transformation } \\
\text { (porphyropsin } \rightarrow \text { rhodopsin); } \beta- \\
\text { crystallin induction }\end{array}$ \\
\hline Skin & $\begin{array}{c}\text { Restructuring; skin granular gland } \\
\text { formation; keratinization and } \\
\text { hardening; apoptosis }\end{array}$ & $\begin{array}{c}\text { Induction of collagen, } 63 \mathrm{kDa} \text { (adult) } \\
\text { keratin and magainin; induction of } \\
\text { collagenase }\end{array}$ \\
\hline Limb bud, lung & $\begin{array}{l}\text { Do novo formation of bone, skin, } \\
\text { muscle, nerves, and so forth. }\end{array}$ & $\begin{array}{l}\text { Cell proliferation and differentiation; } \\
\text { chondrogenesis }\end{array}$ \\
\hline Tail, gills & Complete regression & $\begin{array}{l}\text { Programmed cell death induction and } \\
\text { activation of lytic enzymes } \\
\text { (collagenase, nucleases, phosphatases, } \\
\text { and matrix metalloproteinases); } \\
\text { lysosome proliferation }\end{array}$ \\
\hline $\begin{array}{l}\text { Pancreas, } \\
\text { Intestine }\end{array}$ & Major tissue restructuring & $\begin{array}{l}\text { Reprogramming of phenotype, } \\
\text { induction of proteases, fatty acid } \\
\text { binding protein, and stromelysin-3 }\end{array}$ \\
\hline Immune system & Redistribution of cell populations & $\begin{array}{l}\text { Altered immune system and } \\
\text { appearance of new immunocompetent } \\
\text { components }\end{array}$ \\
\hline Muscle & Growth and differentiation; apoptosis & Induction of myosin heavy chain \\
\hline
\end{tabular}

See $[11,34]$ for details.

orchestrated such diverse effects. Is there a single mechanism of action that governs this diversity of responses or is each manifestation of hormonal activity the result of a different mechanism? At first, physiologists and biochemists attempted to explain the mechanisms underlying their actions as being common to all hormones, but as increasing numbers of hormones became available as pure substances, and as the biochemical and physiological endpoints were better characterized, there was a move away from a generic mechanism of hormone action. Furthermore, as our understanding of complex whole-body physiological processes progressed from biochemical mechanisms, such as enzymology, to receptor analysis, to structural cell biology, to genetic networks, so did the explanations for hormone action continue to evolve.

\section{Early Studies on the Mechanism of Action of TH}

Table 3 summarizes the progression of some major ideas concerning the mechanism of thyroid hormone action following the synthesis of thyroxine, that is, over the fifty years until around 1980. By the early 1930s, it was thought, the activation or inhibition of a given enzyme resulting from the interaction between the hormone and the enzyme could explain the physiological action of the hormone [2]. For example, the stimulation by $\mathrm{T}_{4}$ or $\mathrm{T}_{3}$ of oxygen consumption by isolated tissues or that of BMR in vivo was explained on the basis of a direct interaction between the hormone and some dehydrogenases, the phenomenon often termed allosteric or conformational changes in the enzyme. These direct hormone-enzyme interaction models were eventually discarded because of serious methodological discrepancies, for example, the concentrations of hormone used in vitro would be several orders of magnitude higher than it would ever occur in vivo, or that biologically inactive analogues of the hormone would be often more active than the natural hormone in direct interactions.

The realization that the regulation of biochemical functions in vivo had to be considered in the context of complex cellular structures led to models which took into account the structural organization of physiological activities. Major advances, both technical and conceptual, in the 1950s and early 1960s introduced the idea that the cell membrane, the mitochondrion, the protein synthesizing machinery, and the cell nucleus constituted valid targets for hormones, vitamins, drugs, and other biologically active molecules [13]. Although already in the 1940s Levine had demonstrated that insulin controlled sugar metabolism by interacting with its transport machinery residing in the cell membrane, it was the discovery of cyclic AMP (cAMP) by Sutherland and Rall in 1956 as a "second messenger" of adrenaline and glucagon followed by the equally important discovery that adenylyl cyclase was located in the plasma membrane firmly 
TABLE 3: Milestones in the search for mechanism of thyroid hormone action.

\begin{tabular}{|c|c|}
\hline Year/Period & Milestone \\
\hline 1905 & $\begin{array}{l}\text { Starling introduces the word hormone and the } \\
\text { concept of chemical messengers }\end{array}$ \\
\hline 1911 & $\begin{array}{l}\text { Mammalian thyroid extracts shown to induce } \\
\text { amphibian metamorphosis }\end{array}$ \\
\hline 1919 & $\begin{array}{l}\text { Thyroxine and cortisone extracted and chemically } \\
\text { characterized by Kendall }\end{array}$ \\
\hline 1920-1935 & $\begin{array}{l}\text { Effects of thyroid hormone on tissue and whole } \\
\text { body respiration and metabolic functions }\end{array}$ \\
\hline $1925-45$ & $\begin{array}{l}\text { Isolation and characterization of pituitary protein } \\
\text { hormones }\end{array}$ \\
\hline $1935-50$ & $\begin{array}{l}\text { Hormone-enzyme interactions thought to explain } \\
\text { hormone action }\end{array}$ \\
\hline $1941-55$ & $\begin{array}{l}\text { Insulin and other hormones shown to regulate } \\
\text { transport processes }\end{array}$ \\
\hline $1955-62$ & $\begin{array}{l}\text { Thyroxine thought to act by uncoupling oxidative } \\
\text { phosphorylation }\end{array}$ \\
\hline 1956 & $\begin{array}{l}\text { Discovery of cyclic AMP by Sutherland and the } \\
\text { concept of "second messenger" }\end{array}$ \\
\hline 1960 & $\begin{array}{l}\text { Ecdysteroids induce chromosomal puffing during } \\
\text { insect development-first indication of hormone } \\
\text { action at the nucleus }\end{array}$ \\
\hline 1962 & $\begin{array}{l}\text { Oestradiol shown to bind to nuclear proteins. First, } \\
\text { indication of nuclear receptors }\end{array}$ \\
\hline $1962-66$ & $\begin{array}{l}\text { Steroid and thyroid hormones and retinoids } \\
\text { selectively regulate protein synthesis and } \\
\text { transcription }\end{array}$ \\
\hline 1975-85 & $\begin{array}{l}\text { Protein hormone receptors located in cell } \\
\text { membranes identified as homologues of c-erbB } \\
\text { oncogene; protein phosphorylation cascades } \\
\text { identified }\end{array}$ \\
\hline 1979-89 & $\begin{array}{l}\text { Steroid/thyroid/retinoid receptors cloned as a large } \\
\text { family of c-erbA-related transcription factors } \\
\text { interacting with target genes and modifying } \\
\text { chromatin structure }\end{array}$ \\
\hline $1990 \mathrm{~s}$ & $\begin{array}{l}\text { Crystal structures for many hormone receptors and } \\
\text { partners. Transgenesis and mutagenesis of } \\
\text { receptors in vivo }\end{array}$ \\
\hline 1996 & $\begin{array}{l}\text { Coactivators and corepressors modulate gene } \\
\text { expression by TR and other nuclear receptors }\end{array}$ \\
\hline 1998 & $\begin{array}{l}\text { Phosphorylation, acetylation, and methylation of } \\
\text { TR and other nuclear receptors, histones, and } \\
\text { chromosomal proteins }\end{array}$ \\
\hline 2002-2010 & $\begin{array}{l}\text { Convergence of hormonal signals via membrane } \\
\text { and nuclear receptors. Emergence of concepts of } \\
\text { systems biology, bioinformatics and gene, and } \\
\text { metabolic networking applicable to hormone } \\
\text { action }\end{array}$ \\
\hline
\end{tabular}

established the view that the cell membrane is a major site of action for hormones [14].

At almost the same time as cyclic AMP was discovered, Knox demonstrated that glucocorticoids regulate hepatic metabolism by selectively enhancing the synthesis of the enzyme tyrosine aminotransferase [15]. New methods to study cell-free protein synthesis and the availability of specific transcription inhibitors allowed a more precise analysis of how growth and developmental hormones influenced protein synthesis in their respective target cells. The resulting observations that all steroid and thyroid hormones administered in vivo affect the protein synthesizing machinery in vitro soon shifted the focus on transcriptional control [16]. In the mid-1960s, several investigators were able to reproduce the transcriptional effects of steroid and thyroid hormones in cell-free transcription systems using isolated nuclei and nuclear extracts from target tissues following hormonal administration in vivo. Kinetics of labelling of nuclear RNA further revealed that all steroid and thyroid hormones strongly influence the formation and turnover of messenger RNA.

In 1961, Jensen had made the important observation that highly radioactive estradiol very rapidly (within minutes) accumulated in the nucleus of its target tissues (see [17]). This and subsequent investigations laid the foundation of the concept of nuclear receptors for steroid and thyroid hormones, retinoids, vitamin $\mathrm{D}_{3}$, and so forth. A decade later, Oppenheimer carried out a similar investigation on the selective nuclear localisation of radioactive $\mathrm{T}_{3}$ in rat liver [18]. The main significance of this finding is that the accumulation of the hormone anticipated by several hours the stimulation of transcription, translation, and cellular respiratory responses to this hormone in other cellular organelles of the same tissue under identical conditions. This is schematically illustrated in Figure 1. What is particularly important in this kind of time-course representation of different cellular responses is that inhibition of transcription abolishes the subsequent, different responses and biological activities of thyroid hormone in different mammalian and amphibian biochemical functions, such as protein synthesis, respiration, morphogenesis, and cell death [3, 19]. Although the binding of $\mathrm{TH}$ and steroid hormones to target cell nuclei exhibited many of the functional characteristics of receptors, one had to wait till the technologies of gene cloning had been well established to make the next important step of establishing the nature of nuclear receptors, their organization in cellular structures, and their functional significance.

\section{Later Studies on the Mechanism of Action of TH}

The first indication that hormonal signals regulate transcription was, however, provided by gene puffing in polytenic chromosomes in larval salivary glands of insects, such as Drosophila and Chironomus, during their metamorphosis induced by the molting hormone ecdysone $[20,21]$. These puffs, which contain newly synthesised RNA from sequential activation of specific genes, can be precociously induced by incubating the target cells with ecdysteroids. Kinetics of labelling of nuclear RNA revealed that all steroid and thyroid hormones strongly influenced the formation and turnover of messenger RNA. In the mid-1960s, several investigators were able to reproduce the effects of in vivo administration of 


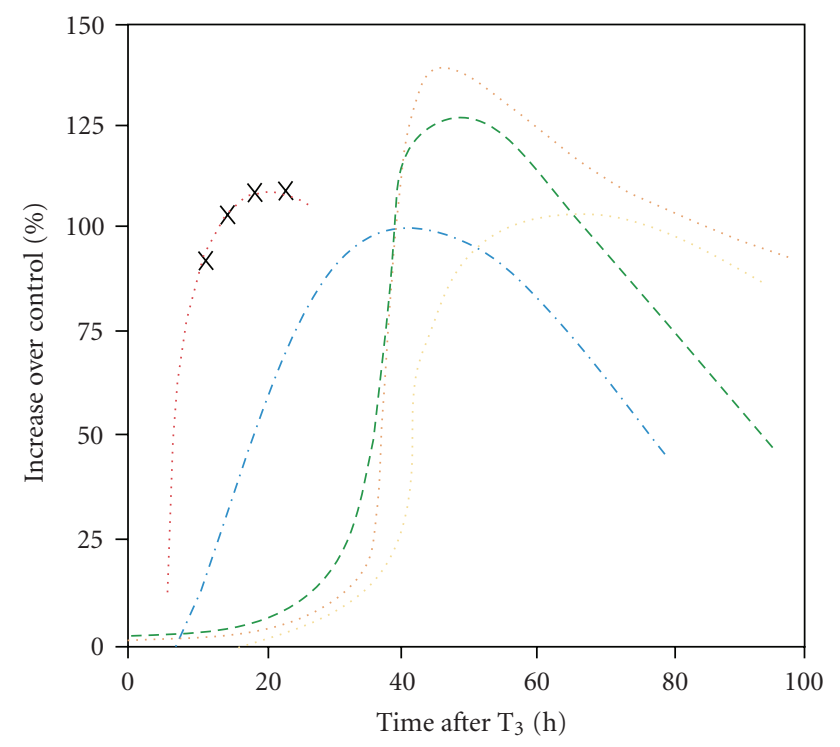

Uptake of labelled $\mathrm{T}_{3}$

Amino acid incorporation by microsomes Cytochrome oxidase

- - - Amino acid incorporation into protein by mitochondria Nuclear RNA polymerase

FIGURE 1: An idealized representation of the time course of response of some activities of nuclei, mitochondria, and microsomes from livers of thyroidectomized rats after a single injection of $20 \mu \mathrm{g}$ $\mathrm{T}_{3} / 100 \mathrm{~g}$. body wt. The stimulatory effects are expressed as $\%$ increase in specific activity in the different subcellular fractions from $\mathrm{T}_{3}$-injected animals over control animals. The main features are the following: (a) mitochondrial respiration (here expressed as cytochrome oxidase activity) reached a peak after amino acid incorporation into protein by microsomes and mitochondria; (b) the increase in protein synthetic capacity of the two organelles was coupled, following a relatively long lag period after hormone administration; (c) nuclear RNA polymerase activity was enhanced several hours before cytoplasmic protein synthesis and BMR. The time course of nuclear accumulation of $\mathrm{T}_{3}(\times \cdots \times$; [18]) is superimposed on that of the hormonal effects on mitochondrial, transcriptional, and protein synthetic activities (Data assembled from [22-24]).

the hormone in cell-free transcription systems using isolated nuclei and nuclear extracts from target tissues of steroids and TH [16].

When Jensen and colleagues tracked the sex hormone oestradiol- $17 \beta$ of high specific radioactivity to female accessory sexual tissues, such as uterus and vagina, it was found to accumulate in the nucleus as a complex with a protein which fulfilled the criteria for a receptor [17, 25]. Following the work from the laboratories of Chambon, Evans, and Vennstrom in the 1980s on the cloning of ER, TR, and GR, more than 35 nuclear receptors have been cloned, sequenced, and obtained as pure recombinant proteins, including several termed as "orphan" receptors, that is, whose ligands remain unknown. All nuclear receptors, which are products of the oncogene v-erbA, function as ligand-activated zinc-finger transcription factors with a modular structure comprising six domains [7, 26-28]. Nuclear hormone receptors can be subdivided into two groups, according to whether they form cytoplasmic complexes with hsp90 and are active as monomer and homodimer or as heterodimers. All vertebrate steroid hormone receptors belong to the first category, while the liganded receptors for retinoic acid, TR, vitamin $\mathrm{D}_{3}$ (VDR), and peroxisome proliferator (PPAR) function as heterodimers with RXR, the 9-cis-retinoic acid receptor. This group of receptors exist as multiple isoforms, the multiplicity residing in the $\mathrm{N}$-terminus of the receptor, which is a wellestablished characteristic of TRs present as TR $\alpha$ and $\operatorname{TR} \beta$, often exhibiting quite distinct functions.

An interesting question arises as to how the high degree of target gene specificity for a given hormone and its receptor is achieved within the above group of nuclear receptors comprising TR. The answer lies in the highly precise spacing of nucleotide repeats in the hormone response element (HRE) of the promoter of the target gene and the DNAbinding domain (DBD) of the receptor which recognises it. Interestingly, the HREs of the nonsteroid receptors, that is, TR, RAR, RXR, VDR, and PPAR, all share the same AGGTCA hexad but are organised as direct repeats (DRs) separated by one to five nucleotides. This arrangement of HREs explains the fine discrimination of target genes by the heterodimers formed by each of these receptors with RXR and which confers an extraordinary hormonal specificity. It is a most remarkable biochemical example of selective transcriptional regulation, confirmed for TR by NMR spectroscopy and Xray crystal structure analysis [29]. Another interesting feature of TRs is that in the absence of its ligand (TH) it acts as a strong inhibitor of transcription, a property that is reversed upon the addition of $\mathrm{TH}$ [30]. In fact, Roeder and his colleagues have exploited this unique characteristic of TR to dissect biochemically the individual steps involved in eukaryotic gene transcription. An ever-increasing number of nonreceptor proteins are now known to interact with nuclear receptors and transcription factors, and that these complexes may function synergistically or in a mutually antagonistic manner [16]. For example, large protein molecules termed CBP (CREB binding protein) and p300 are thought to form bridges between nuclear hormone receptors, including TR, and other transcription factors. This conclusion was arrived at by the unexpected observation that nuclear receptors inhibit the activity of the nonreceptor transcription factor $\mathrm{AP}-1$ by competing for limited amounts of $\mathrm{CBP} / \mathrm{p} 300$ normally present in cells. Other important elements of the complex are the p160 nuclear receptor co-activator and the $270 \mathrm{kDa}$ nuclear receptor corepressor $(\mathrm{N}-\mathrm{CoR})$, which have been purified and their functions tested. Evans and collaborators undertook a structural and thermodynamic analysis of the interaction domains of CBP and the p160 coactivators of TR and RAR to elucidate the assembly of the multiprotein activation complex. They describe a mechanism of mutual synergistic folding whereby the coactivators recruit $\mathrm{CBP} / \mathrm{p} 300$ to facilitate the transmission of the hormonal signal to the transcriptional machinery [29]. Indeed, these examples of protein-protein interactions may just be the tip of an iceberg, and future studies on how TR function can be modified by other nuclear and extranuclear entities may turn out to be quite rewarding. 


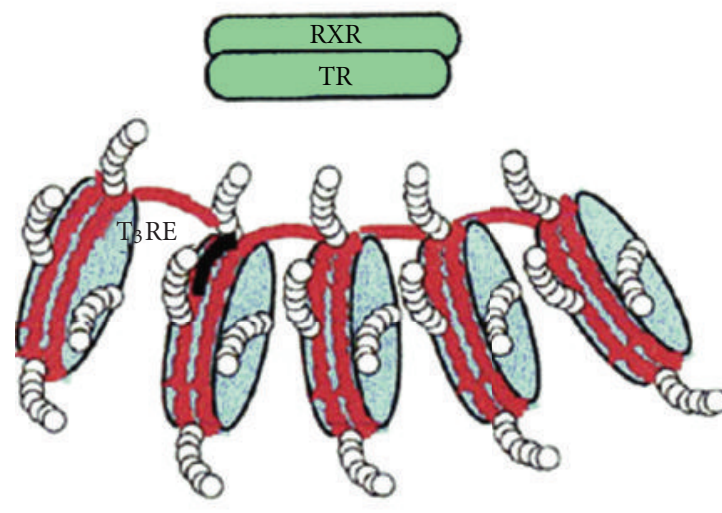

Normal chromatin:

Basal levels of histone acetylation and transcription

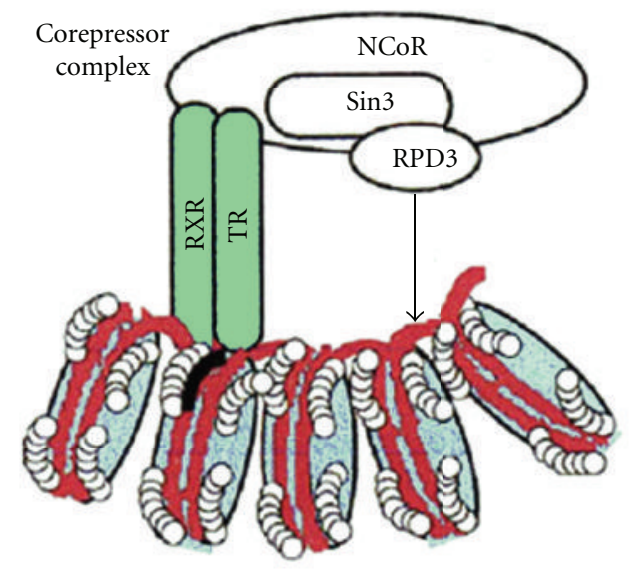

Repressive chromatin:

Deacetylated histones and no transcription

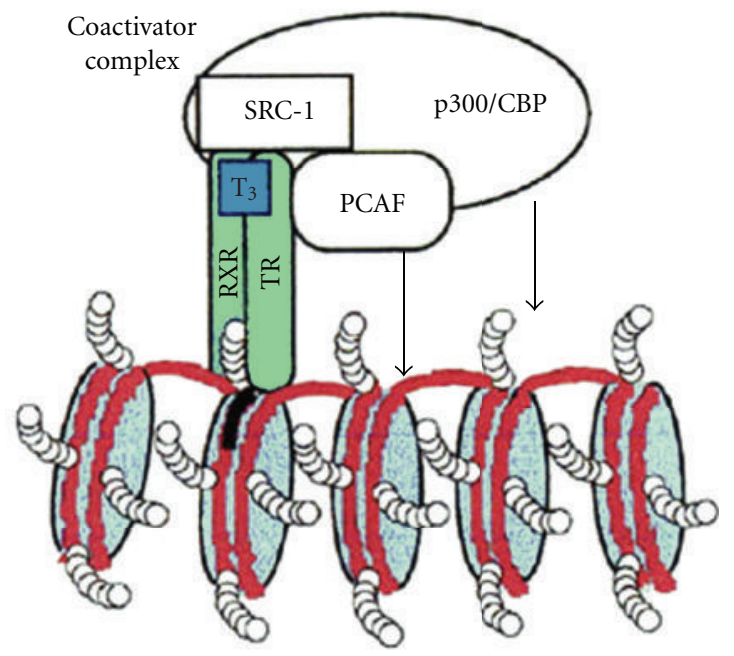

Active chromatin:

High levels of histone acetylation and transcription

FIGURE 2: A representation by Wolffe [8] of how a ligand-activated nuclear receptor could modify the higher-order structure of chromatin. The packaging of DNA into chromatin is visualized in three transcriptionally active states: normal, repressive, and active. In this example, the region of chromatin chosen contains the thyroid hormone receptor (TR)/RXR heterodimer, with or without its ligand triiodothyronine $\left(\mathrm{T}_{3}\right)$, bound to the thyroid responsive element (TRE) in the target gene. In normal chromatin, histone acetylation is at its basal level and so is the transcriptional activity. In the absence of $\mathrm{T}_{3}$ (as during early stages of development), chromatin exists in its condensed and transcriptionally repressive form whereby the histones are in a largely deacetylated state with no transcription of the TR's target gene. In the presence of $\mathrm{T}_{3}$, the chromatin is now active with elevated levels of histone acetylation and transcription. The other components are proteins that form "corepressor" and "coactivator" complexes with complexes with the TR/RXR receptor heterodimer. For more details, see [8]. 
The significance of protein-protein interactions, in the context of regulation of transcription by $\mathrm{TH}$ via TR, has been extended to cell structure by Wolffe [8]. As described schematically in Figure 2, changes in chromatin structure, induced by histone modifications, in the presence and absence of $\mathrm{T}_{3}$ are thought to underly the hormonal regulation of expression of specific genes (details in legand to Figure 2).

\section{Expression of TR Genes}

The expression of the two TH receptor genes TR $\alpha$ and $\mathrm{TR} \beta$ in Xenopus tadpoles is under developmental control [31]. Very small amounts of both TR transcripts can be detected in unfertilized eggs and early embryos. A substantial increase, particularly of TR $\alpha$ mRNA, occurs at around stage 44 , which, quite significantly, is when the Xenopus tadpole first exhibits competence to respond to exogenous thyroid hormone. At this stage of development, several tissues which are programmed to undergo major changes later during metamorphosis show high concentrations of TR mRNA, such as brain, liver, limb buds, small intestine, and tail. After stage 54 and until the completion of metamorphosis, there is good correlation between the accumulation of TR transcripts and the circulating level of thyroid hormone in Xenopus tadpoles $[32,33]$. The relative amounts of $\operatorname{TR} \alpha$ and $\beta$ mRNAs vary according to the tissue of the tadpole and also according to the progression of metamorphosis. There is a possibility, not yet firmly proven, that the multiplicity of $\mathrm{TH}$ actions may in part arise from the two TR isoforms acting on different cellular or biochemical targets. Several studies from the laboratories of Brown, Shi, and Tata have established that administration of exogenous $\mathrm{T}_{3}$ to premetamorphic stages of Xenopus tadpoles causes a substantial induction of TR mRNA [12, 34, 35]. The same phenomenon of "autoinduction" of TR mRNA is observed for Xenopus tadpole tails following exposure to $\mathrm{TH}$ in vivo and in organ culture, a tissue programmed not for further morphogenesis but for cell death and total regression [19]. In all these studies, the extent of "autoinduction" is more marked for TR $\beta$ mRNA than for TR $\alpha$. Also, the upregulation of TR $\beta$ mRNA can be seen as early as $4 \mathrm{~h}$ after the exposure of these premetamorphic tadpoles to exogenous $\mathrm{T}_{3}$, which is among the most rapid biochemical responses of Xenopus tadpoles to the hormone. The exact period preceding the autoinduction of TR $\beta$ receptor can vary according to the experimental conditions in different laboratories and can vary according to the stage of development of the tadpole or whether one adds the hormone to the whole organism, isolated tissues, or cell cultures. There is also the possibility that some other biochemical response may occur before the upregulation of the receptor. It has been suggested that such an earlier responsive element, as for example BTEB1, may be involved in the autoinduction of the TH receptor [36]. Nevertheless, it is important to consider in this context that $\mathrm{TR} \beta$ is a directresponse gene, namely, that its upregulation occurs in the absence of protein synthesis and that the promoter in its gene comprises a fully responsive "thyroid-responsive element" $[34,35]$.
What is the likely mechanism of autoinduction of TRs? The most simple mechanism to explain the phenomenon of auto-regulation would be a direct interaction between TR proteins and the promoters of the genes encoding them [34]. It is significant, as already mentioned, that the promoter of the Xenopus TR $\beta$ gene has two TREs of the more common $\mathrm{DR}+4$ (direct repeat +4 ) type, and that transfection of Xenopus XTC- 2 and XL-2 cells, which express both $\operatorname{TR} \alpha$ and $\beta$ overexpression of unliganded $\operatorname{TR} \alpha$, and $\beta$ in these Xenopus cell lines caused a substantial suppression of basal transcriptional activity. Under the conditions of transcriptional suppression, the addition of $\mathrm{T}_{3}$ to Xenopus cells, cotransfected with the full-length TR $\beta$ promoter, produces up to 20 -fold enhancement of TR gene transcription. Furthermore, these studies have shown that TR-RXR heterodimers, which are the natural form of functional TRs, but not TR monomers or homodimers, specifically interact with the DR+4 TREs of TR $\beta$ gene promoter [37]. These studies strongly support the idea of a direct interaction between the thyroid hormone receptor and the promoter of its own gene as the most likely mechanism underlying Xenopus TR "autoinduction." An indirect approach to understanding the significance of receptor autoinduction would be to look for an intimate association between TR upregulation and the expression of a TH target gene. One such study involved the simultaneous measurement of the expression in premetamorphic Xenopus tadpoles of TR $\beta$ and Xenopus $63 \mathrm{kDa}$ keratin gene, which is only induced by TH during metamorphosis [38]. In stage 52 Xenopus tadpoles (which is before they show signs of metamorphosis), $\mathrm{T}_{3}$ strongly induced simultaneously the accumulation of TR $\beta$ transcripts tadpoles de novo transcription of the adult keratin gene. The same was true if TR upregulation by $\mathrm{T}_{3}$ was inhibited [38]. While such experiments do not establish a direct cause-effect relationship, they strongly suggest the intimate relationship between autoinduction of TR and the activation of the hormone's target genes.

Of wider significance, the phenomenon of autoinduction is not restricted to TR upregulated by TH during amphibian metamorphosis but is also seen with the expression of other nuclear receptors, such as those for steroids and retinoids $[16,21,39]$. A model has been proposed, whereby upregulation of a given receptor is a prerequisite for the sequential activation of its target genes that specify the hormone's biological action [11]. It predicts a double threshold of receptor numbers, the first, or lower level, which would be essential and sufficient for the autoinduction of the receptor and the second, higher threshold for the activation of target genes with which the hormone-receptor complex interacts. It also implies that the gene encoding a given receptor is constitutively expressed to produce a very low level of functional receptor in the target tissue at very early stages of development, which indeed is the case for most growth and developmental hormones and growth factors. One way of validating this model would be to measure the relative affinities of interaction between the DNA-binding domain or hormone-responsive elements in the promoters of the receptor and target genes (which specify the phenotype of biological action of the hormone). 


\section{Single or Multiple Receptors?}

For nearly fifty years until the 1980s, most explanations for the mechanism of action of thyroid hormone were based on a direct interaction of the hormone with individual enzymes, membrane, and other cellular preparations with ligand-binding properties, that is, nongenomic mechanisms ([2]; see Table 3). But the mid-1980s saw a sea change in our thinking about the mechanism of action, not only of $\mathrm{TH}$, but also of all steroid hormones, retinoic acid, and many nonsteroidal signalling molecules, with the discovery of nuclear receptors, that is, signals acting via genomic mechanisms [7, 16, 26, 27]. The powerful tools of gene cloning and sequencing and cell transfection have helped place these later genomic studies on a firmer biochemical base. More recently, however, several investigators have reinvoked the possibility that $\mathrm{TH}$ as well as steroid hormones and other signalling molecules acting via nuclear receptors also exert nongenomic actions through extranuclear sites. The latter is particularly relevant to those that involve rapid responses to the same signal acting relatively slowly via genomic mechanisms (see, e.g., [40-43]). This, in turn, raises the wider question for all hormonal and nonhormonal signals as to whether they operate through the same receptor, perhaps located in different cellular compartments, or whether the different genomic and nongenomic responses are the outcome of interactions with different receptors, irrespective of their locations. While, unlike nuclear receptors, we still await the isolation and precise information on the structure of "nongenomic" receptors, it is of some interest to consider some of the possible situations arising out of whether the multiplicity of responses to a given hormone arise from its interaction with a unique or multiple receptors, as considered below.

As already shown in Table 1, thyroid hormone exerts a wide range of actions in different tissues and organs (e.g., control of metamorphosis in amphibians and basal metabolic rate in mammals). The same is true of signalling molecules. Furthermore, almost all membrane and nuclear hormone receptors are highly conserved as cellular homologues of the oncogenes c-erbB and c-erbA, respectively, which explains why several hormones can functionally interact with their receptors in a wide range of phyla. For example, analogous domains of the receptors of insect hormone ecdysone and the vertebrate thyroid hormone can be swapped to activate transcription in insect and mammalian cells in a reciprocal fashion (see [44]). One is thus faced with the question as to how, if both the hormonal signal and its receptor are conserved through evolution, their physiological actions are not. It underlines the importance of an understanding of the postreceptor "Black Box" in order to move further down the pathway in the search for the mechanism of multiple actions of a given hormone.

To further consider the fact that hormone receptors are evolutionarily conserved, but that their downstream responses are not, three hypothetical, oversimplified, models are presented in Figure 3. First, If one accepts that there is a unique receptor for thyroid hormone in a given cell (model 1), is it possible at some point along the chain of postreceptor downstream responses that there is a point where chains of events diverge, such that it could explain the multiplicity of the physiological actions of the hormone, as shown in Table 1? This possibility of divergence has led some investigators to look for drugs to selectively enhance or block some $\mathrm{TH}$ actions of, as has been implicit in the blocking of cardiac effects, but not cholesterol-lowering effects of, thyroid hormone derivatives [45]. Another possibility for the multiplicity of responses is that the receptor is the same but that it is present in different cellular locations. For example, it has been suggested by some that the nuclear thyroid and steroid hormone receptors are also located in the plasma membrane and mitochondria which could give rise to different actions with different latency periods [40-42]. Recently, Cheng et al. [46] have claimed that the different responses to $\mathrm{TH}$ are initiated not only in the nucleus, but also in the plasma membrane, cytoplasm, and mitochondria (model 2). But firm evidence that these different locations represent distinct functional receptor entities such that each would be responsible for a distinct response to the hormone is however lacking.

The establishment of two distinct receptors for thyroid hormone, $\operatorname{TR} \alpha$ and $\operatorname{TR} \beta$, has allowed the separation of different actions of TH at the receptor level. It has also meant that a well-characterized human thyroid disorder (thyroid hormone resistance) could be explained on the basis of a mutation in one and not the other TR isoform ([43, 47]; see Refetoff, this issue). For some other hormones or cellular signals, it is also possible to explain different responses to the same hormone on the basis of interactions with distinct receptors. For example, the actions of oestrogen via $\operatorname{ER} \alpha$ and $\operatorname{ER} \beta$ (oestrogen receptors $\alpha$ and $\beta$ ) explain the multiplicity of their biological actions as resulting from an initial interaction with distinct receptors in different cell types. This possibility is confirmed by the identification of oestrogen receptors $\alpha$ and $\beta$ present in the different cell types but in the same intracellular location, that is, the nucleus [48].

Another possible model suggests that the multiplicity of action is a reflection of separate postreceptor downstream chains of responses (model 3), but, again, no convincing experimental evidence has been provided. One can invoke other models, such as a modification of that shown in model 3, whereby the action of one hormone acting through one receptor is qualitatively or quantitatively modulated by the downstream action via responses to another receptor (known or unknown) located in a different part of the target cell. The downstream modifications of responses could be compared to how Brivanlou and Darnell [49] conceptualize signals generated from the cell membrane can modify the chain of responses to a signal generated from within the cell, such as from the cell nucleus. The second (or third) signal involved in cross-regulation need not be hormonal in all cases and can be a growth factor, vitamin, antibody, and so forth. Scanning the literature on hormone action in general, many examples can be found whereby one or more hormones can modify the action of another, irrespective of whether or not these hormones act through nuclear or membrane receptors. This is depicted in model 3 of Figure 3 in which hormones $\mathrm{H}_{2}$ and $\mathrm{H}_{3}$ modify the response to $\mathrm{T}_{3}$, 
Model

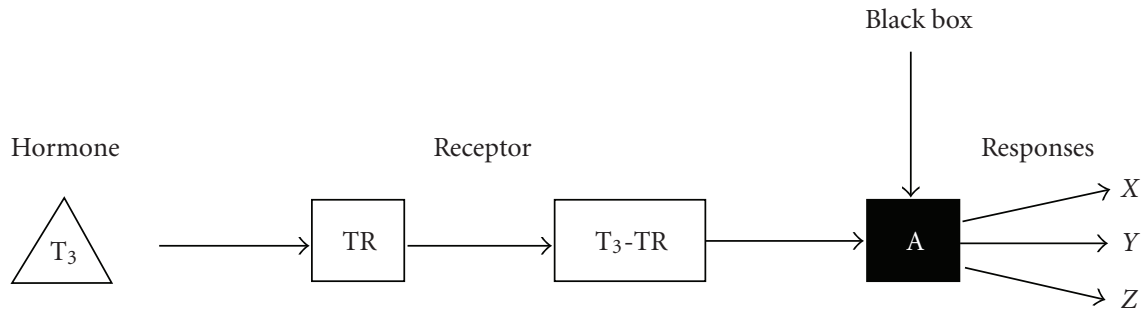

(2)

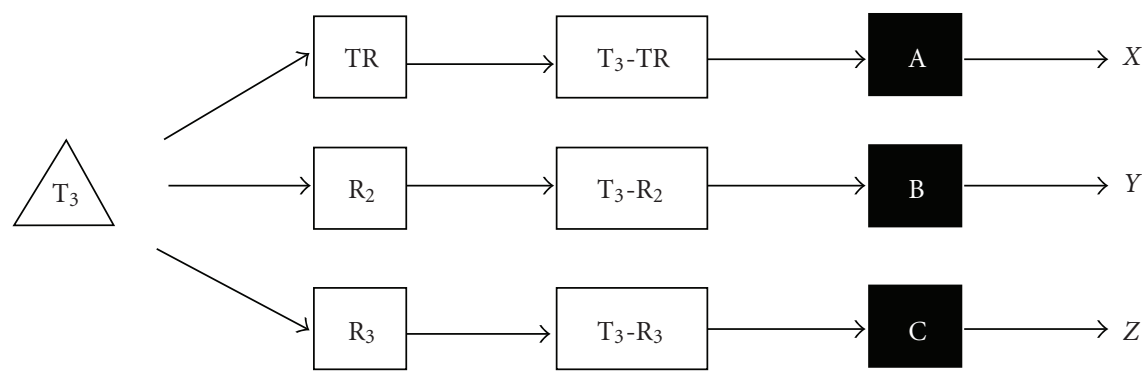

(3)
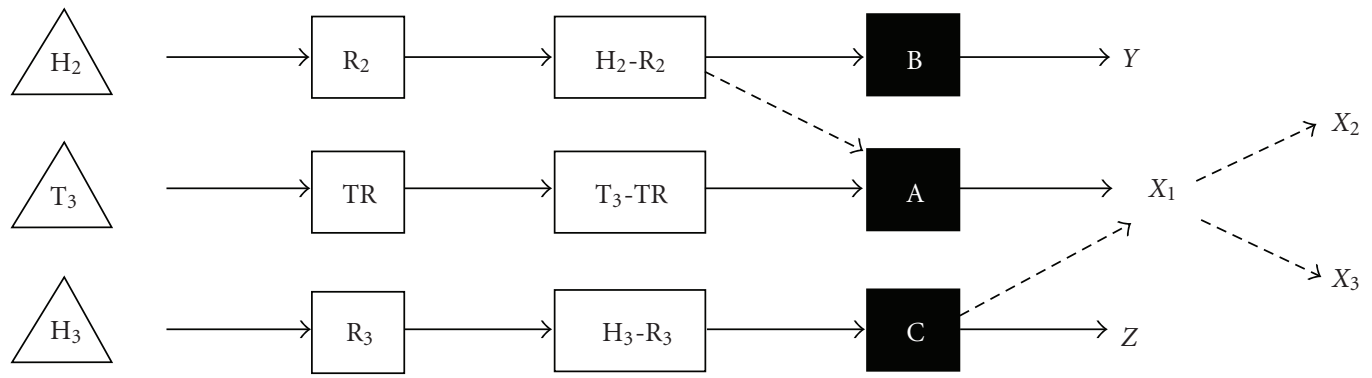

FIGURE 3: Three hypothetical models for thyroid hormone action depicting permutations of multiple hormonal interplay at the postreceptor level, represented by "Black Boxes" A, B, and C. According to model 1, the simplest situation is that $T_{3}$ interacting with a single thyroid hormone receptor (TR) modifies the activity of a key postreceptor complex which gives rise to a chain of multiple responses $X, Y, Z$. The multiplicity of responses to a hormone may also arise from different chemical or structural isoforms of a single receptor, represented in model 2 as TR, $R_{2}$ and $R_{3}$ together giving rise to multiple actions through functionally different Black Boxes. Alternatively, the same single receptor is present in different cellular locations and behaves effectively as different receptors $\left(T R, R_{2}, R_{3}\right)$ in the same or different cells. In model 3, the multiplicity is a function of another hormone or signal $\left(\mathrm{H}_{2}, \mathrm{H}_{3}\right)$, acting via different receptors $\left(\mathrm{R}_{2}, \mathrm{R}_{3}\right)$ to modify the nature, multiplicity, or extent of the action(s) of $\mathrm{T}_{3}$, either before or after the action at the level of Black Boxes. The multiplicity, can also result from further downstream interactions of the postreceptor responses (e.g., $X_{1}, X_{2}$, and $X_{3}$ ).

each acting through its own receptor. Some examples of hormonal cross-regulation can be found in a most recent review [50].

In all three models depicted in Figure 3 , the crucial element is the Black Box. Whereas there has been considerable progress, especially since the molecular cloning of hormonal and nonhormonal receptors, in understanding the fine details of receptor structure, function, and their intermolecular complexes, it has not yet been possible so far to link these data to the final physiological action of a given hormone. It is this gap in our knowledge of receptor function and its relevance to the final physiological action of the hormone (in this case thyroid hormone) that is represented by the Black Boxes in Figure 3. The Black Box could be a onestep or multistep event, the latter most likely if recent ideas of convergence of signals, networking, or proteomics turn out to be the crucial elements for furthering our understanding of mechanisms of hormone action. It represents a major challenge currently to fully understanding the mechanism of hormone action, in contrast to an enormous cataloguing of the effects produced by hormones in order to explain the multiplicity of hormone action. An understanding of the immediate postreceptor response by the target cell to the hormonal signal is essential to enhance our understanding of how hormonal signals accomplish their physiological actions. 


\section{Are We Anywhere Near Discovering the "Mechanism" of Action of Thyroid Hormone?}

A central issue concerning hormone action has been to understand the nature and function of hormone receptors. The application at the end of the 20th century of established and newly emerging technologies of gene cloning, cell transfection, transgenesis and gene knock-out, $\mathrm{X}$-ray crystallography, and NMR analysis of DNA-protein and protein-protein interactions have significantly advanced our understanding of the structure and function of both membrane and nuclear hormone receptors. These advances also point to the important position of cellular homologues of oncogenes in the evolution of cell signalling mechanisms. As regards thyroid hormone, what is most striking from Table 3 is that our views on the mechanism of its action have simply followed the progression of technology needed to understand biological processes in ever more detail. Thus, to answer the main question posed in this review about whether we are any closer to finding the ultimate mechanism of the action of thyroid hormone, the answer has to be a qualified "No." Qualified, because the progression in our search for the mechanism of action of any hormone has been a function of availability of new biochemical, biophysical, genetic, and structural biological technologies. Often, this has simply resulted in the cataloguing of an ever-rapidly accumulation of effects of hormones, but not of their mechanism of action. In other words, the search for the mechanism of hormone action is often largely technology driven and not sufficiently hypothesis based.

So, should one abandon the search for a molecular mechanism of action of thyroid or any other hormone? The answer again is "No." On the contrary, attempts so far to discover the mechanism of hormone action have often led to the discovery of some fundamental principles of biological regulation and signalling. For example, Sutherland and Rall's search for the mechanism underlying how insulin and glucagon regulate metabolic activity in rodent liver [14] led them to discover cyclic AMP which, in turn, unearthed a central pillar of regulatory biology of all living organisms, equally applicable to bacteria, plants, and animals, and not just restricted to hormone action. It was then a relatively short step towards establishing the importance of protein phosphorylation and dephosphorylation in so many vital cellular functions [51], such as energy metabolism, protein and DNA synthesis, and membrane receptor-linked activities, not to mention the subsequent discovery of cyclic GMP and G-proteins, as vital signalling components within cell membranes. Not less important, efforts to unravel the role of thyroid hormone in regulating transcription within the cell nucleus have provided much valuable insight into the multiplicity and functions of RNA polymerases [30] and the importance of structural organisation of chromatin in regulation of gene expression $[8,16]$.

\section{Perspective}

In the 1920s, the increasing availability of pure, nondenatured and biologically active proteins, along with the advances in biochemistry of enzymes, soon led to explanations of mechanisms of thyroid hormone action based on hormone-enzyme interaction. Later, the developments of the methods for subcellular fractionation gave rise to hypotheses based on hormones directly interacting with cell membrane enzymes, mitochondria, ribosomes, and the cell nucleus to explain regulation of energy metabolism, protein synthesis, and transcriptional control. Hormone receptors, as cellular homologues of oncogenes, now occupy a central position in our current thinking of signalling mechanisms, whether located in the cell membrane or the nucleus.

It is certain that increasingly rapid emergence of new molecular, cellular, and physical technologies is going to lead us to re-evaluate the validity and importance of our presentday concepts of mechanisms of hormone action. One can safely predict that, just as in the past, every new technical advance is going to demand a rethinking, modification, or even rejection, of our currently accepted models and introduce new concepts of how thyroid hormone elicits its molecular mechanism of action. What are the most likely developments in the future in our search for the mechanism of thyroid hormone action? The discovery of new factors associated with transcription, such as coactivators, corepressors, and integrators, will continue to define in greater detail how thyroid hormone receptors regulate gene expression; many more modulators will be discovered in the future and that these will be found to form even more complex structures with nuclear hormone receptors [16]. Similarly, it is only in the last decade that the true significance of enzymes that add or remove acetyl and methyl groups in histones and other chromosomal proteins has been realized in the context of a network of cellular signals impinging on nuclear and extranuclear sites. As yet we have uncovered the identity of only a fraction of the approximately 300 chromatin-associated proteins. The recent findings on histone modifications emphasize nucleosome and chromatin structure as dynamic entities that make up the transcriptional machinery and which, in turn, is now leading us to a major shift in our thinking on how thyroid (and steroid) hormones control gene expression [8]. Indeed, Flamant and colleagues have more recently put together a number of different ways in which TH and TRs, together and separately, render the mechanisms of signalling by thyroid hormone much more complex than has been thought of earlier [43].

In a wider perspective, there is an increasing realization that the interaction between different signalling mechanisms operating through membrane, nuclear, and cytoplasmic sites has to be considered as converging mechanisms, rather than as individual or isolated pathways [49]. For example, recently, Kress et al. [9]; (see Plateroti, this issue) have emphasized the importance of considering crosstalk between TH-controlled and other signalling mechanisms. The same group have also highlighted another facet of TH action, namely that the same signal can elicit dual and divergent actions, in this case of cell proliferation and differentiation and further propose that multiple gene networks will also have to be taken into account [10]. They compare the multiplicity of responses to the hormone with what has been 
well known during amphibian metamorphosis where $\mathrm{TH}$ can promote cell growth, differentiation, or cell death in different tissues of the larva [12]. More indirectly, factors governing the availability of thyroid hormone to the receptor, or other sites in the pathway of its action, have also been invoked. For example, the generation or inactivation of $\mathrm{T}_{3}$, the active thyroid hormone, by iodothyronine deiodinases has also to be considered as regulators of thyroid hormone action in controlling metabolism and development $[4,52]$. Clearly, much has yet to be learned about how thyroid hormone signalling regulates specific gene expression and diverse cellular functions from early development to cell death. Finally, all future advances will have to be considered in the context of evolutionary aspects of hormones and their actions, while not losing sight of the history of earlier attempts to explain the mechanism of hormone action.

\section{References}

[1] C. R. Harington, The Thyroid Gland, Its Chemistry and Physiology, Oxford Univ. Press, Oxford, UK, 1932.

[2] R. Pitt-Rivers and J. R. Tata, The Thyroid Hormones, Pergamon Press, London, Uk, 1959.

[3] J. R. Tata, "A hormone for all seasons," Perspectives in Biology and Medicine, vol. 50, no. 1, pp. 89-103, 2007.

[4] D. L. St Germain, V. A. Galton, and A. Hernandez, "Defining the roles of the lodothyronine deiodinases: current concepts and challenges," Endocrinology, vol. 150, no. 3, pp. 1097-1107, 2009.

[5] J. Sap, A. Munoz, K. Damm et al., "The c-erb-a protein is a high-affinity receptor for thyroid hormone," Nature, vol. 324, no. 6098, pp. 635-640, 1986.

[6] R. M. Evans, "The steroid and thyroid hormone receptor superfamily," Science, vol. 240, pp. 889-895, 1988.

[7] G. Benoit, M. Malewicz, and T. Perlmann, "Digging deep into the pockets of orphan nuclear receptors: insights from structural studies," Trends in Cell Biology, vol. 14, no. 7, pp. 369-376, 2004.

[8] A. P. Wolffe, Chromatin: Structure and Function., Academic Press, San Diego, CA, USA., 2000.

[9] E. Kress, A. Rezza, J. Nadjar, J. Samarut, and M. Plateroti, "The frizzled-related sFRP2 gene is a target of thyroid hormone receptor $\alpha 1$ and activates $\beta$-catenin signaling in mouse intestine," Journal of Biological Chemistry, vol. 284, no. 2, pp. 1234-1241, 2009.

[10] E. Kress, J. Samarut, and M. Plateroti, "Thyroid hormones and the control of cell proliferation or cell differentiation: Paradox or duality?" Molecular and Cellular Endocrinology, vol. 313, no. 1-2, pp. 36-49, 2009.

[11] J. R. Tata, Hormonal Signaling and Postembryonic Development, Springer, Berlin, Germany, 1998.

[12] J. R. Tata, "Amphibian metamorphosis as a model for the developmental actions of thyroid hormone," Molecular and Cellular Endocrinology, vol. 246, no. 1-2, pp. 10-20, 2006.

[13] B. Alberts, A. Johnson, J. Lewis, M. Raff, K. Roberts, and P. Walter, Molecular Biology of The Cell, Garland Science, New York, NY, USA, 2008.

[14] E. W. Sutherland, "Studies on the mechanism of hormone action," Science, vol. 177, no. 4047, pp. 401-408, 1972.

[15] W. E. Knox, V. H. Auerbach, and E. C. C. Lin, "Enzymatic and metabolic adaptations in animals," Physiological Reviews, vol. 36, no. 2, pp. 164-254, 1956.
[16] J. R. Tata, "Signalling through nuclear receptors," Nature Reviews Molecular Cell Biology, vol. 3, no. 9, pp. 702-710, 2002.

[17] E. V. Jensen, "From chemical warfare to breast cancer management," Nature Medicine, vol. 10, no. 10, pp. 1018-1021, 2004.

[18] J. H. Oppenheimer and M. I. Surks, "Biochemical basis of thyroid hormone action.", in Biochemical Actions of Hormones, G. Liwack, Ed., vol. III, pp. 119-157, Academic Press, New York,NY,USA, 1975.

[19] J. R. Tata, "Hormonal regulation of programmed cell death during amphibian metamorphosis," Biochemistry and cell biology, vol. 72, no. 11-12, pp. 581-588, 1994.

[20] U. Clever and P. Karlson, "Induktion von puff-veränderungen in den speicheldrüsenchromosomen von chironomus ťentans durch ecdyson," Experimental Cell Research, vol. 20, no. 3, pp. 623-626, 1960.

[21] M. Ashburner, C. Chihara, P. Meltzer, and G. Richards, "Temporal control of puffing activity in polytene chromosomes," Cold Spring Harbor Symposia on Quantitative Biology, vol. 38, pp. 655-662, 1973.

[22] J. R. Tata, L. Ernster, O. Lindbreg, E. Arrhenius, S. Pedersen, and R. Hedman, "The action of thyroid hormones at the cell level," The Biochemical journal, vol. 86, pp. 408-428, 1963.

[23] J. R. Tata, D. B. Roodyn, and K.B. Freeman, "The stimulation by treatment in vivo with triiodothyronine of amino acid incorporation into protein by isolated rat-liver mitochondria," Biochemical, vol. 94, pp. 628-641, 1965.

[24] J. R. Tata and C. C. Widnell, "Ribonucleic acid synthesis during the early action of thyroid hormones," Biochemical Journal, vol. 98, no. 2, pp. 604-620, 1966.

[25] E. V Jensen and H.I. Jacobson, "Basic guides to the mechanism of estrogen action," Recent Progress in Hormone Research, vol. 18, pp. 387-414, 1962.

[26] D. J. Mangelsdorf, C. Thummel, M. Beato et al., "The nuclear receptor superfamily: the second decade," Cell, vol. 83, no. 6, pp. 835-839, 1995.

[27] V. Laudet and H. Gronemeyer, The Nuclear Receptors: Facts Book, Academic Press, NY, USA, 2001.

[28] P. Chambon, "How i became one of the fathers of a superfamily," Nature Medicine, vol. 10, no. 10, pp. 1027-1031, 2004.

[29] D. Chekravarti, V. J. LaMorte, M. C. Nelson et al., "Role of CBP/P300 in nuclear receptor signalling," Nature, vol. 383, no. 6595, pp. 99-103, 1996.

[30] M. Ito and R. G. Roeder, "The TRAP/SMCC/Mediator complex and thyroid hormone receptor function," Trends in Endocrinology and Metabolism, vol. 12, no. 3, pp. 127-134, 2001.

[31] J. R. Tata, "Hormonal interplay and thyroid hormone receptor expression during amphibian metamorphosis," in Metamorphosis. Postembryonic Reprogramming of Gene Expression in Amphibian and Insect Cells, L, I. Gilbert, J. R. Tata, and B. G. Atkinson, Eds., pp. 465-503, Academic Press, San Diego,CA,USA, 1996.

[32] Y. Yaoita and D. D. Brown, "A correlation of thyroid hormone receptor gene expression with amphibian metamorphosis," Genes and Development, vol. 4, no. 11, pp. 1917-1924, 1990.

[33] A. Kawahara, B. S. Baker, and J. R. Tata, "Developmental and regional expression of thyroid hormone receptor genes during Xenopus metamorphosis," Development, vol. 112, no. 4, pp. 933-943, 1991.

[34] Y-B. Shi, Amphibian Metamorphosis. From Morphology to Molecular Biology, John Wiley, NY, USA, 1999. 
[35] D. D. Brown and L. Cai, "Amphibian metamorphosis," Developmental Biology, vol. 306, no. 1, pp. 20-33, 2007.

[36] P. Bagamsbad, K. L. Howdeshell, L. M. Sachs, B. A. Demeneix, and R. J. Denver, "A role for Basic transcription elementbinding protein 1 (BTEB1) in the autoinduction of thyroid hormone receptor $\beta$," Journal of Biological Chemistry, vol. 283, no. 4, pp. 2275-2285, 2008.

[37] I. Machuca, G. Esslemont, L. Fairclough, and J. R. Tata, "Analysis of structure and expression of the xenopus thyroid hormone receptor $\beta$ (xTR $\beta$ ) gene to explain its autoinduction," Molecular Endocrinology, vol. 9, no. 1, pp. 96-107, 1995.

[38] B. S. Baker and J. R. Tata, "Prolactin prevents the autoinduction of thyroid hormone receptor mRNAs during amphibian metamorphosis," Developmental Biology, vol. 149, no. 2, pp. 463-467, 1992.

[39] J. R. Tata, B. S. Baker, I. Machuca, M. L. Rabelo, and K. Yamauchi, "Autoinduction of nuclear receptor genes and its significance," Journal of Steroid Biochemistry and Molecular Biology, vol. 46, no. 2, pp. 105-119, 1993.

[40] A. W. Norman, "Vitamin D receptor: new assignments for an already busy receptor," Endocrinology, vol. 147, no. 12, pp. 5542-5548, 2006.

[41] K. Moriarty, K. H. Kim, and J. R. Bender, "Estrogen receptormediated rapid signaling," Endocrinology, vol. 147, no. 12, pp. 5557-5563, 2006.

[42] J. G. Tasker, D. Shi, and R. Malcher-Lopez, "Rapid glucocrticoid signalling via membrane-associated receptors," Endocrinology, vol. 147, pp. 5549-5556, 2006.

[43] F. Flamant, K. Gauthier, and J. Samarut, "Thyroid hormones signaling is getting more complex: STORMs are coming," Molecular Endocrinology, vol. 21, no. 2, pp. 321-333, 2007.

[44] R. Evans, "A transcriptional basis for physiology," Nature Medicine, vol. 10, no. 10, pp. 1022-1026, 2004.

[45] A. Berkenstam, J. Kristensen, K. Mellstrom et al., "The thyroid hormone mimetic compound KB2115 lowers plasma LDL cholesterol and stimulates bile acid synthesis without cardiac effects in humans," Proceedings of the National Academy of Sciences of the United States of America, vol. 105, no. 2, pp. 663667, 2008.

[46] S. Y. Cheng, J. L. Leonard, and P. J. Davis, "Molecular aspects of thyroid hormone actions," Endocrine Reviews, vol. 31, no. 2, pp. 139-170, 2010.

[47] O. Chassande, A. Fraichard, K. Gauthier et al., "Identification of transcripts initiated from an internal promoter in the c-erbA $\alpha$ locus that encode inhibitors of retinoic acid receptor- $\alpha$ and triiodothyronine receptor activities," Molecular Endocrinology, vol. 11, no. 9, pp. 1278-1290, 1997.

[48] G. G. Kuiper, B. Carlsson, K. Grandien et al., "Comparison of the ligand binding specificity and transcript tissue distribution of estrogen receptors and alpha and beta," Endocrinology, vol. 138, no. 3, pp. 863-870, 1997.

[49] A. H. Brivanlou and J. E. Darnell Jr, "Transcription: signal transduction and the control of gene expression," Science, vol. 295, no. 5556, pp. 813-818, 2002.

[50] P. Bagamsbad and R. J. Denver, "Mechanisms and significance of nuclear receptor auto- and cross-regulation," General and Comparative Endocrinology, vol. 170, pp. 3-17, 2011.

[51] T. Hunter, "Oncoprotein networks," Cell, vol. 88, no. 3, pp. 333-346, 1997.

[52] A. Campos-Barros, L. L. Amma, J. S. Faris, R. Shailam, M. W. Kelley, and D. Forrest, "Type 2 iodothyronine deiodinase expression in the cochlea before the onset of hearing," Proceedings of the National Academy of Sciences of the United States of America, vol. 97, no. 3, pp. 1287-1292, 2000. 


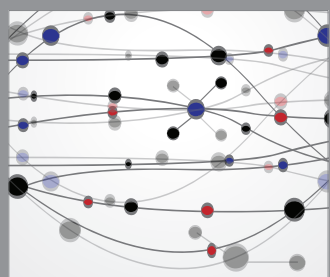

The Scientific World Journal
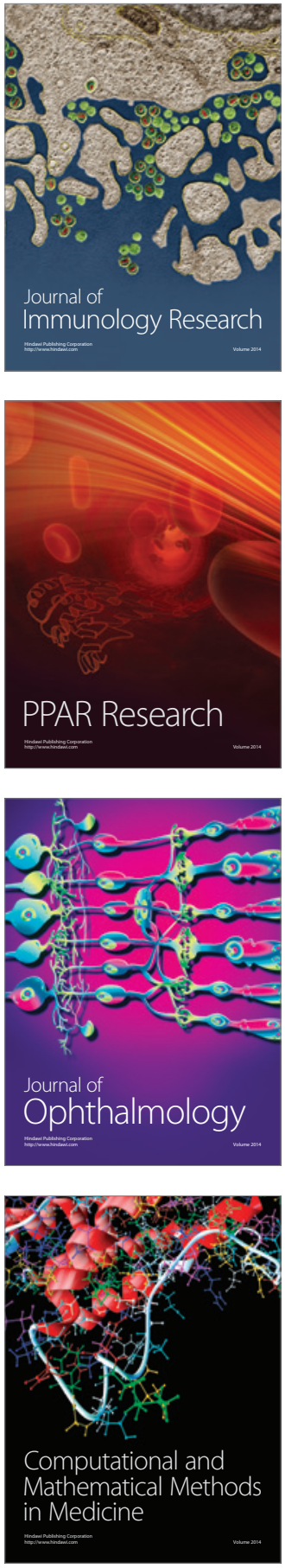

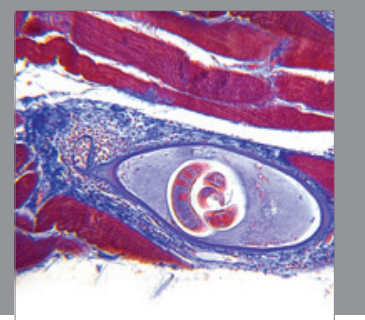

Gastroenterology

Research and Practice
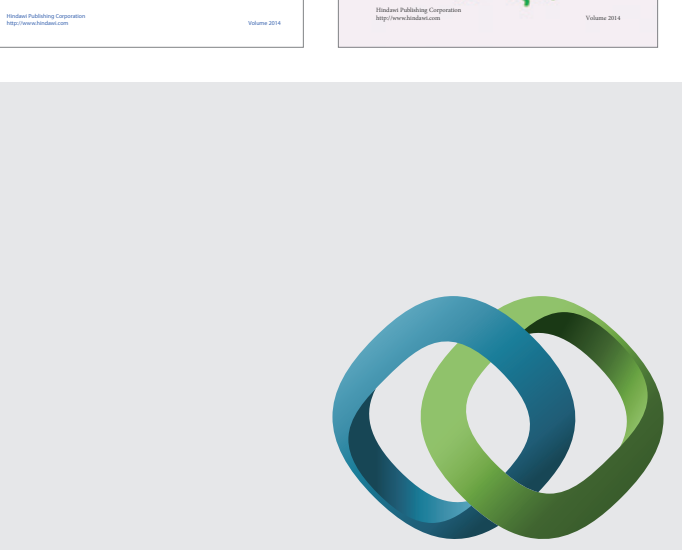

\section{Hindawi}

Submit your manuscripts at

http://www.hindawi.com
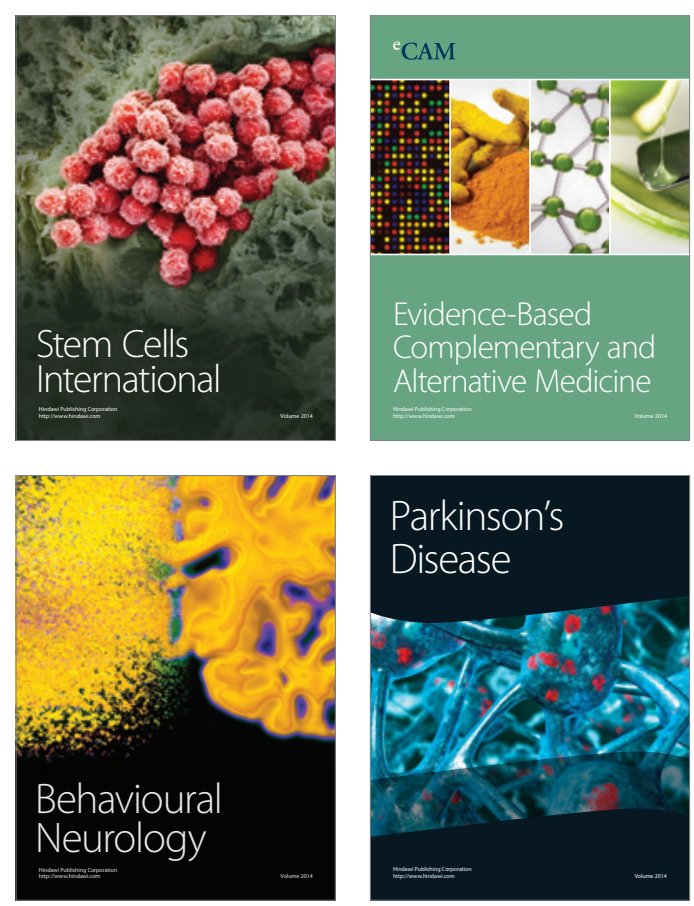

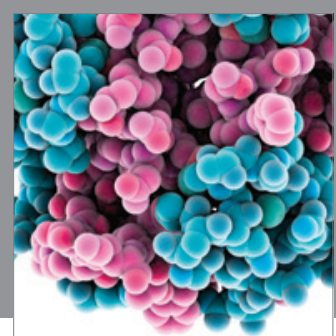

Journal of
Diabetes Research

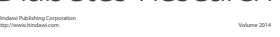

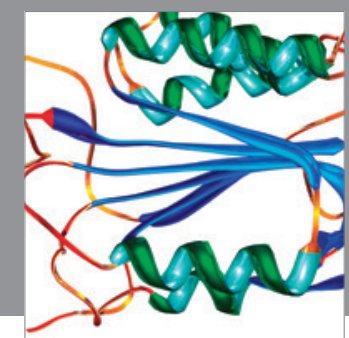

Disease Markers
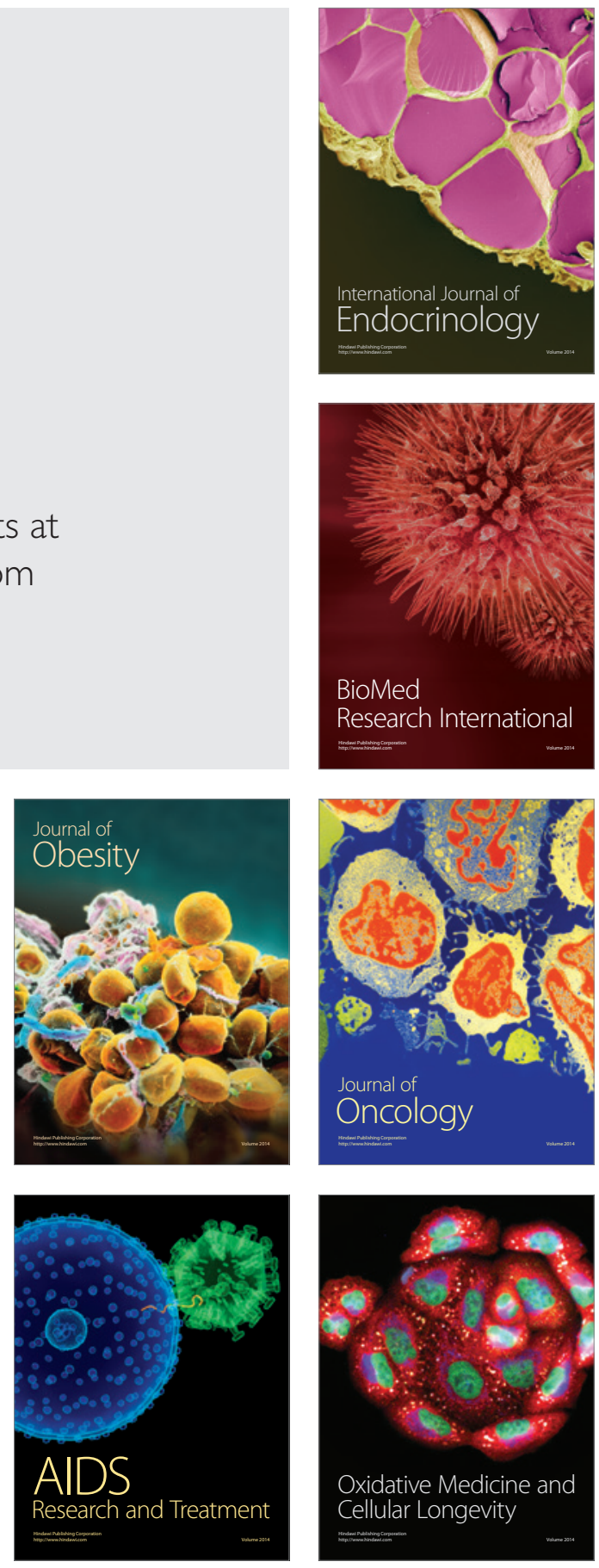